\title{
Circumferential silicone sponge scleral buckling induced axial length changes: case series and comparison to literature
}

\author{
Shira Sheen Ophir, Asaf Friehmann and Alexander Rubowitz ${ }^{*}$
}

\begin{abstract}
Background: This study compared axial length changes induced by circumferential scleral buckling using a silicone sponge with literature reports for solid silicone rubber.

Methods: Records of patients treated with scleral buckling in 2009-2013 using a silicone sponge, with preoperative axial length biometry measurements were reviewed. Additional information included age, type of surgery, additional surgeries, phakic status and anatomical success of reattachment. Patients underwent repeat biometry. The medical literature was reviewed for articles describing axial length changes induced by circumferential buckling using solid silicone rubber.

Results: Twenty-eight patients (mean age 49.7 years, range 16-72) met the inclusion criteria. Mean axial length was $25.38 \mathrm{~mm}$ preoperatively and $26.12 \mathrm{~mm}$ at least 6 months postoperatively (SD $0.50 \pm 0.09, p<0.001$ ); a mean increase of $0.74 \mathrm{~mm}$. Half the patients subsequently underwent cataract surgery. Post-operative changes were not significant compared to pre-surgical refraction and corneal astigmatism. Axial length change was not significant between sexes (9 women and 19 men).

Conclusions: Axial length changes induced by circumferential scleral buckling using silicone sponge exclusively are similar to those reported in the literature for solid silicone rubber buckles. Scleral buckling using a silicone sponge, which may offer several surgical advantages, induces an acceptable axial length change similar to that seen with widely-used solid silicone rubber buckles.
\end{abstract}

Keywords: Silicone sponge, Solid silicone rubber, Axial length, Circumferential buckling, Rhegmatogenous retinal detachment

\section{Background}

Although its popularity has declined in recent years [1], scleral buckling is still commonly used for the treatment of rhegmatogenous retinal detachment, either as a standalone procedure or combined with vitrectomy. Scleral buckling has several drawbacks and unique side effects, including conjunctival scarring, explant exposure or infection, diplopia (usually transient), globe penetration while suturing the explants to the sclera, and others [2-6]. Axial length change, one of the most common side effects of

*Correspondence: arubowi@smile.net.il

Department of Ophthalmology, Meir Medical Center, 59 Tshernichovsky St., Kfar Saba 44281, Israel scleral buckling surgery, is caused by the buckle deforming and indenting the globe, which causes a refractive shift. This common side effect is particularly bothersome in previously emmetropic patients, in patients previously isometropic in whom it may induce anisometropia, and in previously emmetropic pseudophakic patients, who are frustrated by the need for refractive correction in a previously ametropic eye after cataract surgery.

Scleral buckling using solid silicone rubber explants is the most widely used form of buckling surgery, and several publications have documented the axial length changes it induces [7-18]. Our department uses only silicone sponge explants, rather than the solid silicone rubber explants used in most institutions. To the best of our knowledge, axial 
length changes induced exclusively by using silicone sponge buckles have not been well documented. In this study, we sought to determine whether the change in axial length induced by silicone sponge circular explants was significantly different from that reported in the literature for solid silicone explants, and whether one explant material was more advantageous than the other was.

\section{Methods}

Records of all patients who underwent scleral buckling surgery in our department during 2009-2013 by two vitreoretinal senior surgeons (Y.F. and A.R.) using circumferential $7.5 \mathrm{~mm} \times 2.5 \mathrm{~mm}$ silicone sponge explants (Labtician Ophthalmics, Style 511, Oakville, ON, CA) were reviewed. Scleral sutures were placed at $9 \mathrm{~mm}$ width (1.5 mm wider than the sponge), using 5-0 Ethilon (Ethicon US, Somerville NJ, USA) scleral mattress sutures to provide an indentation effect.

Only patients with a successfully attached retina at least six months after surgery, whose charts contained reliable preoperative axial length measurements using the Zeiss IOL Master (Carl Zeiss Meditech, Jena, Germany), without intravitreal silicone oil (which would preclude reliable axial length measurement), and who had circumferential explants placed without additional radial buckling elements were included. Patients with these characteristics were called and invited to participate in the study. Those who chose to participate received an explanation of the study goals and signed an informed consent. Subsequently, they underwent at least three repeated IOL-Master biometry axial length measurements, the axial length measurements were performed by two ophthalmologists (S.S.O. and A.F.)

The charts were reviewed for surgical details, preoperative phakic status, and demographic data such as age and sex. The pre- and post-operative biometrics were compared using paired $t$ test. $p<0.05$ was considered statistically significant. Statistical analyses were performed using SPSS, Inc., version 21.

As approximately half the patients were phakic at the time of their detachment surgery and later had cataract surgery, their refractive status was influenced by differing techniques and intraocular lens types and was therefore not included in the analysis.

The literature was reviewed for articles describing axial length changes caused by circumferential scleral buckling with solid silicone rubber explants or silicone sponge explants, including articles in all languages from 1970 to the present.

\section{Results}

Twenty-eight eyes of 28 patients met the inclusion criteria. Mean age was 49.7 years (range 16-72 years). The mean axial length was $25.38 \mathrm{~mm}$ preoperatively, and $26.12 \mathrm{~mm}$ at least 6 months postoperatively (SD $0.497 \pm 0.094, p<0.001$ ), a mean increase of $0.74 \mathrm{~mm}$ (Table 1).

Refraction did not change significantly after surgery $(-2.78 \mathrm{D}$ before to -3.49 after, SD $2.58 \pm 0.58, p=0.156$, respectively). Axial length change between sexes was not significant (9 women and 19 men). However, more males underwent surgery.

Corneal astigmatism did not change significantly after surgery $(-1.03 \mathrm{D}$ to $-1.39 \mathrm{D}$ respectively, SD $0.75 \pm 0.14$, $p=0.17)$.

\section{Discussion}

Axial length change is a common side effect of scleral buckling surgery. It is caused by the buckle causing an indentation in the globe, which might cause a refractive shift. Our ophthalmology department uses soft, pliable, silicone sponge buckles, as we feel they induce a more gradual and rounded indentation of the globe wall than that seen with solid silicone buckling. We compared this method with the use of solid silicone reported in the literature.

Although numerous articles describe axial length changes after scleral buckling surgery [7-17], the surgeries and methods used, as well as patient characteristics, length of follow-up and measurements reported vary widely. This makes it difficult to establish a standard, acceptable axial length change with the commonly used method of solid silicone rubber buckling, and complicates comparison with the buckling method used in our institution.

Some reports regarding axial length change after scleral buckling used the older method of intra-scleral implants rather than the explants used today $[8-10,14]$. Others included several methods in undisclosed proportions or various surgical methods that were not described $[8,9$, $15,16,18]$, also precluding meaningful comparison.

Sato et al. [14] included only pediatric eyes. This causes additional comparison problems due to the possibility of differing effects of buckling on globe growth and scleral compliance at various ages. Additionally, one article included buckle height measurements but not axial length [9], while others measured axial lengths after very

\section{Table 1 Pre- and postoperative measurements of 28 eyes}

\begin{tabular}{lllll}
\hline $\begin{array}{l}\text { Measure- } \\
\text { ment }\end{array}$ & Preoperative & $\begin{array}{l}\text { Postopera- } \\
\text { tive }\end{array}$ & $\begin{array}{l}\text { Std. Devia- } \\
\text { tion }\end{array}$ & $p$ value \\
\hline $\begin{array}{c}\text { Axial length } \\
\text { (mm) }\end{array}$ & 25.38 & 26.12 & $0.497 \pm 0.094$ & $<0.001$ \\
$\begin{array}{c}\text { Refraction } \\
\text { (diopters) }\end{array}$ & -2.78 & -3.49 & $2.36 \pm 0.52$ & 0.17 \\
$\begin{array}{c}\text { Cylinder } \\
\text { (diopters) }\end{array}$ & -1.03 & -1.39 & $0.75 \pm 0.14$ & 0.17 \\
\hline
\end{tabular}


short or varying and unspecified periods of follow-up $[10,17]$, where the eyes may not have reached their final axial length. Most of these articles included several of the above mentioned limitations.

Previously published articles used A-scan ultrasound to measure axial length, whereas we used optical biometry with the Zeiss IOL-Master. Optical biometry has been shown to yield extremely accurate and reliable axial length measurements, and measurements obtained with these two methods agree closely and are interchangeable [19-23].

The few remaining articles, where exclusively solid silicone buckles and elements were used as explants, with methods described in detail, adequate follow-up and axial length measurements were used as a comparison to our buckling method. Larsen and Syrdalen [11] found that the average axial length increased $0.98 \mathrm{~mm}$ in 10 eyes, Brazitikos et al. [7] reported a mean axial length increase of $0.95 \mathrm{~mm}$ in 75 eyes and MalukiewiczWisniewska and Stafiej [12] showed a mean increase at one year of $0.57 \mathrm{~mm}$ in all 74 eyes. As can be seen in the relevant articles, the mean axial length increased from $0.57 \mathrm{~mm}$ to $0.98 \mathrm{~mm}$ after scleral buckling surgery.

\section{Conclusion}

We found a mean axial length increase of $0.74 \mathrm{~mm}$ at least 6 months after surgery. This is comparable (although possibly closer to the lower end) to that previously described for scleral buckling with solid silicone elements.

We did not find any reports describing axial length changes after scleral explant surgery using a silicone sponge. Although, several papers described axial length changes with combined solid silicone and silicone sponge elements.

In this study, we have shown that axial length changes six months after scleral explant surgery using a silicone sponge are comparable to those described in the literature after solid silicone rubber buckling.

\footnotetext{
Authors' contributions

SSO: Responsible for study conception and design, drafted the manuscript and revised it critically for important intellectual content, gave final approval of the version to be published; and agrees to be accountable for all aspects of the work in ensuring that questions related to the accuracy or integrity of any part of the work are appropriately investigated and resolved. AR: Acquisition of data and analysis and interpretation of data, gave final approval of the version of the submitted manuscript and agrees to be accountable for all aspects of the work in ensuring that questions related to the accuracy or integrity of any part of the work are appropriately investigated and resolved. AF: Responsible for study conception and design of and interpretation of data, revised the draft manuscript and agrees to be accountable for all aspects of the work in ensuring that questions related to the accuracy or integrity of any part of the work are appropriately investigated and resolved. All authors read and approved the final manuscript.
}

\section{Acknowledgements}

Faye Schreiber, MS edited the manuscript.

\section{Competing interests}

The authors have no competing interests to declare.

Availability of data and supporting materials

The deidentified data will be made available on request.

\section{Ethics approval and consent to participate}

The study was approved by the Meir Medical Center Ethics Committee on June 11, 2013, file number 012512. All participants provided signed informed consent.

Received: 7 September 2016 Accepted: 22 February 2017

Published online: 27 March 2017

\section{References}

1. Chong DY, Fuller DG. The declining use of scleral buckling with vitrectomy for primary retinal detachments. Arch Ophthalmol. 2010;128:1206-7.

2. Brucker AJ, Hopkins TB. Retinal detachment surgery: the latest in current management. Retina. 2006;26:S28-33.

3. Charonis A, Chang TS. Anterior segment complications associated with scleral buckling. Ophthalmol Clin North Am. 2004;17:545-56.

4. Chaudhry NL, Durnian JM. Post-vitreoretinal surgery strabismus-a review. Strabismus. 2012;20:26-30.

5. Schwartz SG, Flynn HW Jr, Mieler WF. Update on retinal detachment surgery. Curr Opin Ophthalmol. 2013;24:255-61.

6. Tsui I. Scleral buckle removal: indications and outcomes. Surv Ophthalmol. 2012;57:253-63.

7. Brazitikos PD, Androudi S, Christen WG, Stangos NT. Primary pars plana vitrectomy versus scleral buckle surgery for the treatment of pseudophakic retinal detachment: a randomized clinical trial. Retina. 2005;25:957-64.

8. Burton TC, Herron BE, Ossoinig KC. Axial length changes after retinal detachment surgery. Am J Ophthalmol. 1977;83:59-62.

9. Gopal L, D'Souza C, Bhende M, Fogla S, Ratra D, Shetty NS, et al. Scleral buckling-implant versus explant. Retina. 2003;23:636-40.

10. Kiernan JP, Leveille AS, Morse PH. Axial length following scleral buckling Retina. 1982;2:176-8.

11. Larsen JS, Syrdalen P. Ultrasonographic study on changes in axial eye dimensions after encircling procedure in retinal detachment surgery. Acta Ophthalmol (Copenh). 1979:57:337-43.

12. Malukiewicz-Wisniewska G, Stafiej J. Changes in axial length after retinal detachment surgery. Eur J Ophthalmol. 1999;9:115-9.

13. Okada Y, Nakamura S, Kubo E, Oishi N, Takahashi Y, Akagi Y. Analysis of changes in corneal shape and refraction following sclera buckling surgery. Jpn J Ophthalmol. 2000;44:132-8.

14. Sato T, Kawasaki T, Okuyama M, Ideta H. Refractive changes following scleral buckling surgery in juvenile retinal detachment. Retina. 2003:23:629-35.

15. Smiddy WE, Loupe DN. MIchels RG, Enger C, Glaser BM, deBustros S. Refractive changes after scleral buckling surgery. Arch Ophthal. 1989;107:1469-71.

16. Tanihara H, Negi A, Kawano S, Ishigouoka H, Ueda Y, Yoshida-Suzuki S, Amano H, Satou E, Honda Y. Axial length of eyes with rhegmatogenous retinal detachment. Ophthalmologica. 1993;206:76-82.

17. Vukojević N, Sikić J, Curković T, Juratovac Z, Katusić D, Sarić B, Jukić T. Axial eye length after retinal detachment surgery. Coll Antropol. 2005;29(Suppl 1):25-7.

18. Wang $\mathrm{HZ}$, Chen MT, Chang $\mathrm{CH}$, Tsai MC, Wu WC, Chung CB. The changes of ocular axial length and corneal curvatures after sclera buckling for retinal detachment. Gaoxiong Yi Xue Ke Xue Za Zhi. 1994;10:77-83.

19. Bjeloš Rončević $M$, Bušić M, Cima I, Kuzmanović Elabjer B, Bosnar D, Miletić D. Comparison of optical low-coherence reflectometry and applanation ultrasound biometry on intraocular lens power calculation. Graefes Arch Clin Exp Ophthalmol. 2011;249:69-75.

20. Haigis W, Lege B, Miller N, Schneider B. Comparison of immersion ultrasound biometry and partial coherence interferometry for intraocular lens calculation according to Haigis. Graefes Arch Clin Exp Ophthalmol. 2000;238:765-73. 
21. Hussin HM, Spry PG, Majid MA, Gouws P. Reliability and validity of the partial coherence interferometry for measurement of ocular axial length in children. Eye (Lond). 2006;20:1021-4.

22. Packer M, Fine IH, Hoffman RS, Coffman PG, Brown LK. Immersion A-scan compared with partial coherence interferometry: outcomes analysis. J Cataract Refract Surg. 2002;28:239-42.
23. Rajan MS, Keilhorn I, Bell JA. Partial coherence laser interferometry vs. conventional ultrasound biometry in intraocular lens power calculations. Eye (Lond). 2002;16:552-6.

\section{Submit your next manuscript to BioMed Central and we will help you at every step:}

- We accept pre-submission inquiries

- Our selector tool helps you to find the most relevant journal

- We provide round the clock customer support

- Convenient online submission

- Thorough peer review

- Inclusion in PubMed and all major indexing services

- Maximum visibility for your research

Submit your manuscript at www.biomedcentral.com/submit 